\title{
Effect of cetrimide $2 \%$ with and without photodynamic therapy to reduce Streptococcus mutans burden in dentinal carious lesions
}

\author{
Gabriele Giorgi Moro ${ }^{1}$ (D) Natalia Cunha Massat ${ }^{2}$ (D) Diana Roberta Pereira Grandizoli ${ }^{2}$ (i) \\ Augusto Etchegaray Junior ${ }^{2}$ (D) $\cdot$ Giovanna Rosa Degasperi $^{3}$ (D) Carlos Eduardo Fontana $^{2}$ (D) $\cdot$ Sérgio Luiz Pinheiro ${ }^{2}$ (D)
}

Received: 15 December 2020 / Accepted: 22 March 2021 / Published online: 31 March 2021

(C) The Author(s), under exclusive licence to Springer-Verlag London Ltd., part of Springer Nature 2021

\begin{abstract}
To evaluate the use of cetrimide alone and combined with photodynamic therapy to reduce $S$. mutans burden in carious lesions. Sixty permanent third molars were sectioned and the coronal dentin exposed. A cariogenic challenge was performed using brainheart infusion (BHI) medium supplemented and S. mutans ATCC 25175. Specimens were incubated in anaerobic jars at $37^{\circ} \mathrm{C}$ for 15 days, with BHI renewed every $24 \mathrm{~h}$. After 15 days, specimens were randomly divided into six groups $(n=10)$ : C, control (no treatment); CHX, application of chlorhexidine $2 \%$; CT, application of cetrimide $2 \%$; CT+aPDT, application of cetrimide $2 \%$ followed by methylene blue dye and aPDT (antimicrobial photodynamic therapy: wavelength $660 \mathrm{~nm}$, energy $4 \mathrm{~J}$, power 100 $\mathrm{mW}$, spot size $0.0028 \mathrm{~cm}^{2}$, energy density $142 \mathrm{~J} / \mathrm{cm}^{2}$ for $40 \mathrm{~s}$ ); ES+aPDT, application of experimental solution (methylene blue dye with cetrimide) and aPDT; and aPDT alone. Carious tissue from each specimen was collected before and after the applications. Five decimal dilutions were performed, and the resulting solution was seeded in mitis-salivarius-bacitracin agar. Plates were incubated in anaerobic jars at $37^{\circ} \mathrm{C}$ for $48 \mathrm{~h}$. Analysis of variance (ANOVA) with post hoc Tukey's test was used to compare total S. mutans counts. Significant reductions in S. mutans were observed after application of CT+aPDT (0.30 (0.97), $p$ $<0.0001)$ and ES+aPDT $(0.52(1.13), p<0.0001)$. Cetrimide $2 \%$ with methylene blue dye, applied consecutively or as a mixture, can be used as a photosensitizing agent for aPDT to reduce $S$. mutans burden in dentinal caries.
\end{abstract}

Keywords Cavity disinfection $\cdot$ S. mutans $\cdot$ Laser irradiation $\cdot$ Photodynamic therapy $\cdot$ Cetrimide (cetrimonium)

\section{Introduction}

Minimally invasive restorative dentistry techniques involve selective removal of the carious lesion while preserving affected but still repairable dentin. Cavity disinfection plays a key role in eliminating residual bacteria in this substrate, preventing the formation of secondary caries and postoperative sensitivity. Several antimicrobials are used for this

Sérgio Luiz Pinheiro

slpinho@puc-campinas.edu.br

1 Department of Restorative Dentistry, Pontifical Catholic University of Campinas (PUC Campinas), Campinas, SP, Brazil

2 Center for Life Sciences, Postgraduate Program in Health Sciences, PUC Campinas, Av. John Boyd Dunlop, s/n, Campinas, SP 13034-685, Brazil

3 Center for Health Sciences, PUC-Campinas, Campinas, SP, Brazil purpose, particularly chlorhexidine (CHX), the most popular agent for cavity cleaning [1-3].

CHX has been used to disinfect decayed dental tissue since the 1970s [4]. Due to its broad antimicrobial spectrum, it has been used in endodontics, periodontics, and treatment of carious lesions [5]. CHX is a cationic compound which interacts with anions in the bacterial cell wall (phosphate groups of teichoic acids in Gram-positive bacteria and lipopolysaccharides in Gram-negative bacteria) [6]. The bacteriostatic effects of CHX are exerted through the release of low-molecularweight substances [7].

Cetrimide (CT) is an alternative to CHX with similar properties. CT is a cationic surfactant of the quaternary ammonium class with proven effectiveness against Grampositive and Gram-negative bacteria, as well as antifungal activity $[8,9]$. It is used topically and is entirely nontoxic at a concentration of up to $2 \%$ [10]. As a mixture of amphipathic molecules, CT reduces the surface tension of liquids [11]. This characteristic could facilitate its 
penetration in hard-to-reach areas such as the inner lumen of dentinal tubules [12].

Antimicrobial photodynamic therapy (aPDT) is another technique that has been used in the treatment of carious lesions [13]. A light source is used to activate a photosensitizer such as methylene blue, which, in the presence of oxygen, forms singlet oxygen and other free radicals that lead to the irreversible rupture of cellular components, alter signal transduction pathways, and disrupt metabolic functions, ultimately leading to cell death [14]. This technique has been shown to reduce bacterial and fungal contamination in vivo [15].

In the context of the ongoing COVID-19 pandemic, minimal intervention techniques that reduce bioaerosol generation during dental practice are effective and should be considered [16-18]. In addition, the main advantages of photodynamic treatment in inactivating microorganisms are its broad spectrum of action and the non-development of resistance mechanisms. Cost-effective photosensitizers, such as phenothiazines or porphyrins, might also help mitigate the spread of COVID19, considering their effectiveness against SARS-CoV-2 [19, 20]. Therefore, aPDT could be an alternative for the minimally invasive treatment of deep carious lesions while increasing safety for patients and practitioners [16].

There is no evidence to prove the effectiveness of cetrimide as a disinfectant for cavities, whether alone or in combination with aPDT. Therefore, the objective of this study was to evaluate the use of cetrimide alone and combined with photodynamic therapy to reduce $S$. mutans counts in dentinal caries. The null hypothesis was that there would be no significant difference in the reduction of $S$. mutans burden in decayed dentin with the use of cetrimide alone versus combined with aPDT.

\section{Materials and methods}

The present study was approved by the institution Research Ethics Committee (protocol number 2.167.351 and 1.230.452). Sixty unerupted permanent third molars, with no visible cracks or fractures under $\times 10$ magnification (Carl Zeiss, São Paulo, SP, Brazil), were selected from the institution dental clinic. The chemical compounds used in this study are described in Table 1.

\section{Sample size calculation}

The sample size was calculated using analysis of variance (ANOVA). With a minimum difference between treatment means of 0.22 , standard error of 0.125 , number of treatments $=6$, statistical power $=0.80$, and alpha $=0.05$, the number of teeth per group was defined as 10 .

\section{Specimens}

After sample selection, the occlusal third was removed from each specimen using a double-sided diamond disk (KG Sorensen Indústria e Comércio Ltda., São Paulo, SP, Brazil) in a low-speed handpiece ( $\mathrm{KaVo}$ do Brasil Indústria e Comérciol Ltda., Joinville, SC, Brazil), under refrigeration, to expose the dentin surface. The dentin surfaces were polished with wet silicon carbide sandpaper sheets, P600 grit (Água T223 advance, Norton, São Paulo, SP, Brazil). A 4×4mm label (3M do Brasil Ltda., São Paulo, SP, Brazil) was placed onto the dentin surface of each specimen to standardize the location of the carious lesion. The specimens were sealed using epoxy resin (Araldite, São Paulo, SP, Brazil) and nail polish (Colorama, São Paulo, SP, Brazil), except on the region covered by the label. The label was then removed to enable generation of the carious lesion. After waterproofing, the specimens were sterilized with ethylene oxide (Acecil, Campinas, SP, Brazil).

\section{Cariogenic challenge}

Teeth were then exposed to a cariogenic challenge in brainheart infusion (BHI) broth (Acumedia, Neogen Corporation, Lansing, MI, USA), supplemented with $1 \%$ glucose (Labsynth Materiais para Laboratório Ltda., Diadema, SP, Brazil), $1 \%$ sucrose (Labcenter Materiais para Laboratórios, Campinas, SP, Brazil), 0.5\% yeast extract (Oxoid Ltd., Basingstoke, HPH, UK), and S. mutans type strain ATCC 25175 (Fundação André Tosello, Campinas, SP, Brazil), standardized to 0.5 McFarland turbidity. Samples were incubated in anaerobic jars (Probac do Brasil, São Paulo, SP, Brazil) at $37^{\circ} \mathrm{C}$ and subsequently stored in a bacteriological incubator (Sterilifer Indústria e Comércio Ltda., Diadema, SP, Brazil) for 15 days. During this period, BHI broth was replaced every $24 \mathrm{~h}$ (adapted from Carvalho et al. [21] and Lima et al. [22]).

\section{Study interventions}

After 15 days, the specimens were randomly distributed (www.random.org.br) according to the cavity disinfection procedure $(n=10)$, as shown in Table 2.

\section{Assessment of cariogenicity}

The collected samples were immediately placed in BHI transport medium (Acumedia, Neogen Corporation, Lansing, MI, USA) and homogenized for $1 \mathrm{~min}$ in a tube shaker (Phoenix, Araraquara, SP, Brazil). Immediately after homogenization, five decimal dilutions were performed into test tubes (Uniglass Produtos para Laboratórios Ltda., Cascavel, PR, Brazil), and three $25-\mu \mathrm{L}$ aliquots from each dilution were seeded with a micropipette (Uniscience do Brasil, São 
Table 1 Chemical compounds used in the study, manufacturer, and city/country of manufacture

\begin{tabular}{ll}
\hline Cetrimide & Neofórmula, Campinas, SP, Brazil \\
\hline Chlorhexidine & Dental Cremer Produtos Odontológicos S.A, Blumenau, SC, Brazil \\
Experimental solution & Cetrimide-Neofórmula, Campinas, SP, Brazil \\
& Methylene blue 0.01\%-DMC Importação e Exportação de Equipamentos Ltda., Sao Carlos, SP, Brazil \\
Epoxy resin & Araldite, Sao Paulo, SP, Brazil \\
Nail polish & Colorama, Sao Paulo, SP, Brazil \\
Brain-heart infusion (BHI) broth & Acumedia, Neogen Corporation, Lansing, MI, USA \\
Glucose & Labsynth Materiais para Laboratório Ltda., Diadema, SP, Brazil \\
Sucrose & Labcenter Materiais para Laboratórios, Campinas, SP, Brazil \\
Yeast extract & Oxoid Ltd., Basingstoke, HPH, UK \\
S. mutans type strain ATCC 25175 & Fundação André Tosello, Campinas, SP, Brazil \\
Mitis-salivarius-bacitracin (MSB) medium & Oxoid Ltd., Basingstoke, HPH, UK; Merck KGaA, Darmstadt, HE, Germany \\
\hline
\end{tabular}

Paulo, SP, Brazil) onto the surface of mitis-salivariusbacitracin (MSB) medium (Oxoid Ltd., Basingstoke, HPH, UK; Merck KGaA, Darmstadt, HE, Germany). All plates (Olen, China) were incubated in anaerobic jars (Probac do Brasil, São Paulo, SP, Brazil) at $37{ }^{\circ} \mathrm{C}$ (candle-flame method) for $48 \mathrm{~h}$. After incubation, the viable bacterial count was determined in $\mathrm{CFU} / \mathrm{mL}$.

\section{Statistical analyses}

Statistical analyses were carried out in BioEstat 4.0. The Shapiro-Wilk test of normality was applied. The sample was normally distributed. Comparisons of reduction in microbial counts were performed by ANOVA with Tukey's post hoc test at the $1 \%$ significance level.

\section{Results}

The arithmetic means and standard deviations of the $S$. mutans count of each sample group (CFU/mL-log10) are described in Table 2. After cetrimide application combined with aPDT (CT + aPDT), $S$. mutans counts decreased significantly $(0.30$ [0.97], $p<0.0001)$. The experimental solution plus aPDT

Table 2 Description of study groups by disinfection procedure

\begin{tabular}{|c|c|}
\hline Groups & Procedure \\
\hline $\mathrm{C}$ & $\begin{array}{l}\text { S. mutans count after curettage of carious lesion with a sterile \#5 spoon excavator (Millenium, Golgran Indústria Comercial de } \\
\text { Instrumentos Odontológicos Ltda., São Caetano do Sul, SP, Brazil); no further disinfection }\end{array}$ \\
\hline $\mathrm{CT}$ & $\begin{array}{l}\text { S. mutans count after application of } 2 \% \text { cetrimide (Neofórmula, Campinas, SP, Brazil) for } 1 \text { min with a microbrush (KG Sorensen } \\
\text { Medical Burs Indústria e Comércio de Produtos Abrasivos Ltda., Cotia, SP, Brazil) }\end{array}$ \\
\hline CHX & $\begin{array}{l}\text { S. mutans count after application of } 2 \% \text { chlorhexidine (Dental Cremer Produtos Odontológicos S.A, Blumenau, SC, Brazil) for } 1 \text { min } \\
\text { with a microbrush (KG Sorensen Medical Burs Indústria e Comércio de Produtos Abrasivos Ltda., Cotia, SP, Brazil) }\end{array}$ \\
\hline $\mathrm{CT}+\mathrm{aPDT}$ & $\begin{array}{l}\text { S. mutans count after application of } 2 \% \text { cetrimide (Neofórmula, Campinas, SP, Brazil) for } 1 \text { min, followed by antimicrobial } \\
\text { photodynamic therapy with } 0.01 \% \text { methylene blue photosensitizer (DMC Importação e Exportação de Equipamentos Ltda., São } \\
\text { Carlos, SP, Brazil), applied for } 3 \text { min with a microbrush (KG Sorensen Medical Burs Indústria e Comércio de Produtos Abrasivos } \\
\text { Ltda., Cotia, SP, Brazil). Subsequently, low-level laser (DMC Importação e Exportação de Equipamentos Ltda., São Paulo, SP, } \\
\text { Brazil; wavelength }=660 \mathrm{~nm} \text {, energy }=4 \mathrm{~J} \text {, power }=100 \mathrm{~mW} \text {, spot size }=0.0028 \mathrm{~cm}^{2} \text {, energy density }=142 \mathrm{~J} / \mathrm{cm}^{2} \text { ) was applied for } 40 \mathrm{~s}\end{array}$ \\
\hline $\mathrm{ES}+\mathrm{aPDT}$ & $\begin{array}{l}\text { S. mutans count after application of an extemporaneously compounded mixture of } 2 \% \text { cetrimide (Neofórmula, Campinas, SP, Brazil) } \\
\text { and } 0.01 \% \text { methylene blue (DMC Importação e Exportação de Equipamentos Ltda., São Carlos, SP, Brazil) with a microbrush (KG } \\
\text { Sorensen Medical Burs Indústria e Comércio de Produtos Abrasivos Ltda., Cotia, SP, Brazil) for } 4 \text { min. Subsequently, low-level laser } \\
\text { (DMC Importação e Exportação de Equipamentos Ltda., São Paulo, SP, Brazil; wavelength }=660 \mathrm{~nm} \text {, energy = } 4 \mathrm{~J} \text {, power }=100 \\
\mathrm{~mW} \text {, spot size }=0.0028 \mathrm{~cm}^{2} \text {, energy density }=142 \mathrm{~J} / \mathrm{cm}^{2} \text { ) was applied for } 40 \mathrm{~s}\end{array}$ \\
\hline aPDT & $\begin{array}{l}\text { S. mutans count after photodynamic therapy with } 0.01 \% \text { methylene blue (DMC Importação e Exportação de Equipamentos Ltda., São } \\
\text { Carlos, SP, Brazil), applied for } 3 \text { min with a microbrush (KG Sorensen Medical Burs Indústria e Comércio de Produtos Abrasivos } \\
\text { Ltda., Cotia, SP, Brazil). Subsequently, low-level laser (DMC Importação e Exportação de Equipamentos Ltda., São Paulo, SP, } \\
\text { Brazil; wavelength }=660 \mathrm{~nm} \text {, energy }=4 \mathrm{~J} \text {, power }=100 \mathrm{~mW} \text {, spot size }=0.0028 \mathrm{~cm}^{2} \text {, energy density }=142 \mathrm{~J} / \mathrm{cm}^{2} \text { ) was applied for } 40 \\
\text { s }\end{array}$ \\
\hline
\end{tabular}

$a P D T$, antimicrobial photodynamic therapy; $C$, control; $C H X$, chlorhexidine; $C T$, cetrimide; $E S$, experimental solution 
group (ES + aPDT), which did not differ significantly from the CT + aPDT group, also presented a low $S$. mutans count $(0.52$ [1.13]).

aPDT alone also reduced $S$. mutans counts (1.97 [0.32]), however with no difference to the CHX group (2.58 [0.92]), which, in turn, did not differ significantly from the $\mathrm{CT}$ group (3.03 [0.45]). Individually, all groups differed significantly from the control group (4.53 [0.43]), which presented the highest $S$. mutans counts $(p<0.01)$, as described in Tables 3 and 4.

\section{Discussion}

The present study used the microbiologic caries challenge methodology. Briefly, with the aid of orthodontic wires, teeth were secured in glass jars containing BHI medium supplemented with $1 \%$ glucose, $1 \%$ sucrose, $0.5 \%$ yeast extract, and a type strain of $S$. mutans (ATCC 25175) standardized to $0.5 \mathrm{McF}$ arland turbidity. To induce the carious lesion, the specimens were incubated in an oven at $37{ }^{\circ} \mathrm{C}$ for 15 days in anaerobic jars, using the candle flame method. During this period, the BHI medium was renewed every $24 \mathrm{~h}$ and the $\mathrm{pH}$ was measured to ensure an acidic medium conducive to the presence of bacterial activity (around $\mathrm{pH} 4.5$ ) $[14,15]$. In vitro models are commonly used to simulate the cariogenic challenge and to analyze the cariostatic effects of different materials; however, it is noteworthy that in vitro studies provide only simplified insight into the in vivo oral environment, as they do not provide for the properties of saliva, erosive tooth wear, or even oral hygiene habits. In addition, the duration of in vitro experiments is often shorter than in vivo studies [16-18]. There are other models for the production of artificial caries; the chemical model uses acid gel or solutions that stimulate the tooth demineralization process. Studies have compared the depth of caries produced in dentin by microbiological and chemical models and have shown that the microbiological model achieves greater caries depth. In addition, it produces decayed tissue with more demineralization and well-defined tubules, while the chemical model produces a more dense, compact structure, without well-defined dentinal tubules $[19,20]$. These factors are relevant to the result of the present study, and justify the method used.

Surface-associated bacterial biofilms are complex, threedimensional structures in which bacteria are incorporated into
Table 4 Arithmetic means and SD of the S. mutans counts of each sample group $\left(\mathrm{CFU} / \mathrm{mL}-\log _{10}\right)$. In columns, different capital letters denote significant differences among groups $(p<0.0001)$. Lowercase letters denote no differences between groups $(p<0.0001)$

\begin{tabular}{lll}
\hline Groups & Mean (SD) & \\
\hline C & $4.53(0.43)$ & B \\
CT & $3.03(0.45)$ & A \\
CHX & $2.58(0.92)$ & Aa \\
aPDT & $1.97(0.32)$ & Ca \\
ES + aPDT & $0.52(1.13)$ & D \\
CT + aPDT & $0.30(0.97)$ & D \\
\hline
\end{tabular}

$a P D T$, antimicrobial photodynamic therapy; $C$, control; $C F U$, colony formation unit; $C H X$, chlorhexidine; $C T$, cetrimide; $E S$, experimental solution; $S D$, statistical deviation

a matrix composed of extracellular polymeric substances, which provide mechanical stability to the biofilm and provide several functions that allow its organization [23]. Once formed, biofilms are difficult to remove completely. Several chemical agents capable of acting on the biofilm are often employed for this purpose, including surfactants. As a cationic surfactant, cetrimide has cytotoxic bactericidal action and can act on biofilms $[18,19]$. It is mostly non-irritating to host tissues and has the capacity to reduce the surface tension of liquids, facilitating their entry into hard-to-reach areas, such as the dentinal tubules [20]. Accordingly, a previous study found that application of cetrimide $0.2 \%$ for 1 min achieved eradication of $S$. mutans in most specimens, as well as an increase in the rate of biofilm removal [24]. Another study showed that cetrimide $0.2 \%$ has longer-lasting substantivity compared to chlorhexidine $0.2 \%$ and almost as long as that of chlorhexidine $2 \%$ in a dentine model [21]. This may be related to the cationic nature of cetrimide, which is able to interact with dentin. These studies point to the potential use of cetrimide and are in line with the results of the present work, in which cetrimide application reduced $S$. mutans burden in dentinal caries.

aPDT is an antimicrobial technique used in the treatment of oral infections, such as tooth decay. It consists of the application of light to activate a photosensitive agent in the presence of oxygen, generating reactive oxygen species (such as singlet oxygen) in situ and resulting in bacterial lysis [22]. When used on dentin, aPDT has been found to decrease $S$. mutans counts in deep carious lesions [25]. In addition, another study
Table 3 Arithmetic means and standard deviations of the S. mutans count of each sample group (CFU/mL-log 10$)$

\begin{tabular}{llllllc}
\hline C & CHX 2\% & CT 2\% & CT + aPDT & ES + aPDT & aPDT & (p-ANOVA) \\
\hline $4.53(0.43)$ & $2.58(0.92)$ & $3.03(0.45)$ & $0.30(0.97)$ & $0.52(1.13)$ & $1.97(0.32)$ & $<0.0001$ \\
\hline
\end{tabular}

$a P D T$, antimicrobial photodynamic therapy; $C$, control; $C F U$, colony formation unit; $C H X$, chlorhexidine; $C T$, cetrimide; $E S$, experimental solution 
evaluated the use of aPDT (application of toluidine blue for 3 $\mathrm{min}$ ) in periodontal pockets and found in a reduction in the number of bacteria [26]. Gong et al. demonstrated a significant reduction in $S$. mutans, L. casei, and Candida albicans counts after aPDT, using the photosensitizer erythrosine for 3 min and a blue light-emitting diode (LED), resulting in a significant antimicrobial effect against oral biofilms [27]. The results of the present study are consistent with the literature; a reduction in $S$. mutans counts was obtained with aPDT, with the same duration of photosensitizer application, and no difference in the reduction of $S$. mutans counts with the addition of cetrimide, whether as a separate step or in a mixed experimental solution, both followed by low-level laser irradiation. Therefore, the null hypothesis was confirmed.

Ornellas et al. demonstrated the effectiveness of methylene blue $(0.01 \%$ applied for $5 \mathrm{~min})$ followed by red laser irradiation in reducing the total number of Streptococcus spp., S. mutans, and Lactobacillus spp. [28]. The advantage of aPDT is that it reduces the microbial load of dentin immediately. Ricatto et al. further demonstrated the effectiveness of methylene-blue PDT, with a laser or LED light source, in reducing S. mutans and L. casei burden [29]. Guglielmi et al. [24] observed a reduction in total microorganism counts (S. mutans, Lactobacillus spp.) during an in vivo study evaluating the effect of methylene-blue PDT on contaminated dentin of permanent teeth. Again, the results are in line with the present study, as PDT was able to significantly reduce $S$. mutans burden in carious lesions.

An additional advantage of aPDT concerns the ongoing pandemic of coronavirus disease 2019 (COVID-19), caused by the SARS-CoV-2 virus originating in China [25]. Because this virus is transmitted via respiratory droplets and bioaerosols or contact with contaminated surfaces [30], the pandemic has had an impact on aerosolgenerating dental procedures [26]. As these aerosols can spread for considerable distances and remain suspended in the air for several hours, the dental clinic environment is thus a high-risk area for nosocomial spread [23]. Use of atraumatic, noninvasive, or minimally invasive treatment techniques that promote minimal or near-zero generation of bioaerosols would be safer, especially considering the high success rate that these treatments have in dentistry [16].

In short, this study found that combining cetrimide - a cationic surfactant capable of penetrating the deeper layers of the dentinal tubules - with aPDT was able to promote deeper penetration of photosensitizer (methylene blue $0.01 \%$ ) into the tubules, thus allowing better disinfection of the carious lesion and consequent eradication of $S$. mutans. This is a minimally invasive technique with reduced aerosol generation, which makes it particularly suitable for the current context of COVID-19. Nevertheless, additional studies are needed to evaluate the potential of cetrimide and photosensitizer combinations, particularly in a single experimental solution, as a means of streamlining the procedure.

\section{Conclusion}

Based on the results of this in vitro study, aPDT with a combination of cetrimide $2 \%$ plus a photosensitizing agent reduced $S$. mutans CFU counts in dentinal caries. This protocol is a promising, minimally invasive alternative to conventional techniques which involves minimal bioaerosol generation, thus making it safer for clinical practice during the COVID19 pandemic.

Author contribution All authors contributed to the study conception and design. Material preparation, data collection and analysis were performed by Gabriele Giorgi Moro, Natalia Cunha Massat, Diana Roberta Pereira Grandizoli, Augusto Etchegaray Junior, Giovanna Rosa Degasperi, Carlos Eduardo Fontana, and Sérgio Luiz Pinheiro. The first draft of the manuscript was written by Sérgio Luiz Pinheiro, and all authors commented on previous versions of the manuscript. All authors read and approved the final manuscript.

\section{Declarations}

Ethics approval All procedures performed in studies involving human participants were in accordance with the ethical standards of the institutional research committee and with the 1964 Helsinki declaration and its later amendments or comparable ethical standards. The present study was approved by the local Research Ethics Committee (protocol numbers 2.167.351 and 1.230.452).

Consent to participate Written informed consent was obtained from the donors of all teeth used in this study.

\section{References}

1. de Almeida Neves A, Coutinho E, Cardoso MV, Lambrechts P, Van Meerbeek B (2011) Current concepts and techniques for caries excavation and adhesion to residual dentin. J Adhes Dent 13:7-22. https://doi.org/10.3290/j.jad.a18443

2. Banerjee A (2003) Minimal intervention dentistry: part 7 . Minimally invasive operative caries management: rationale and techniques. Br Dent J 214:107-111. https://doi.org/10.1038/sj. bdj.2013.106

3. Benerjee A, Frencken JE, Schwendicke F, Innes NPT (2017) Contemporary operative caries management: consensus recommendations on minimally invasive caries removal. Br Dent J 223: 215-222. https://doi.org/10.1038/sj.bdj.2017.672

4. Kaspar JR, Godwin MJ, Velsko IM, Richards VP, Burne RA (2019) Spontaneously arising Streptococcus mutans variants with reduced susceptibility to chlorhexidine display genetic defects and diminished fitness. Antimicrob Agents Chemother 63:e00161e00119. https://doi.org/10.1128/AAC.00161-19

5. Carrilho MR, Carvalho RM, Sousa EN, Nicolau J, Breschi L, Mazzoni A, Tjäderhane L, Tay FR, Agee K, Pashley DH (2010) Substantivity of chlorhexidine to human dentin. Dent Mater 26: 779-785. https://doi.org/10.1016/j.dental.2010.04.002 
6. Estrela C, Ribeiro RG, Estrela CR, Pécora JD, Sousa-Neto MD (2003) Antimicrobial effect of 2\% sodium hypochlorite and 2\% chlorhexidine tested by different methods. Braz Dent J 14:58-62. https://doi.org/10.1590/S0103-4402003000100011

7. Gomes BP, Ferraz CC, Vianna ME, Berber VB, Teixeira FB, Souza-Filho FJ (2001) In vitro antimicrobial activity of several concentrations of sodium hypochlorite and chlorhexidine gluconate in the elimination of Enterococcus faecalis. Int Endod J 34:424 428. https://doi.org/10.1046/j.1365-2591.2001.00410.x

8. Vieira DB, Carmona-Ribeiro AM (2006) Cationic lipids and surfactants as antifungal agents: mode of action. J Antimicrob Chemother 58:760-767. https://doi.org/10.1093/jac/dkl312

9. Ruiz-Linares M, Ferrer-Luque CM, Arias-Moliz T, de Castro P, Aguado B, Baca P (2014) Antimicrobial activity of alexidine, chlorhexidine and cetrimide against Streptococcus mutans biofilm. Ann Clin Microbiol Antimicrob 13:41. https://doi.org/10.1186/s12941014-0041-5

10. Cloete TE, Jacobs L, Brözel VS (1998) The chemical control of biofouling in industrial water systems. Biodegradation 9:23-37. https://doi.org/10.1023/a:1008216209206

11. Jennings MC, Minbiole KP, Wuest WM (2015) Quaternary ammonium compounds: an antimicrobial mainstay and platform for innovation to address bacterial resistance. ACS Infect Dis 1:288-303. https://doi.org/10.1021/acsinfecdis.5b00047

12. Giardino L, Ambu E, Becce C, Rimondini L, Morra M (2006) Surface tension comparison of four common root canal irrigants and two new irrigants containing antibiotic. J Endod 32:10911093. https://doi.org/10.1016/j.joen.2006.05.008

13. Santin GC, Oliveira DS, Galo R, Borsatto MC, Corona SA (2014) Antimicrobial photodynamic therapy and dental plaque: a systematic review of the literature. ScientificWorldJournal 2014:824538. https://doi.org/10.1155/2014/824538

14. Paschoal MA, Duarte S, Santos-Pinto L (2013) Photodynamic antimicrobial chemotherapy for prevention and treatment of dental caries: a critical review. AO Dentistry 1:1-5. https://doi.org/10. 13172/2054-2526-1-1-946

15. Pinheiro SL, Schenka AA, Neto AA, de Souza CP, Rodriguez HM, Ribeiro MC (2009) Photodynamic therapy in endodontic treatment of deciduous teeth. Lasers Med Sci 24:521-526. https://doi.org/10. 1007/s10103-008-0562-2

16. Al-Halabi M, Salami A, Alnuaimi E, Kowash M, Hussein I (2020) Assessment of paediatric dental guidelines and caries management alternatives in the post COVID-19 period. A critical review and clinical recommendations. Eur Arch Paediatr Dent 16:543-556. https://doi.org/10.1007/s40368-020-00547-5

17. Ali K, Raja M (2020) Coronavirus disease 2019 (COVID-19): challenges and management of aerosol-generating procedures in dentistry. Evid Based Dent 21:44-45. https://doi.org/10.1038/s41432020-0088-4

18. Pollitt KJG, Peccia J, Ko AI, Kaminski N, Cruz CSD, Nebert DW, Reichardt JKV, Thompson DC, Vasiliou V (2020) COVID-19 vulnerability: the potential impact of genetic susceptibility and airborne transmission. Hum Genomics 14:17. https://doi.org/10. 1186/s40246-020-00267-3

19. Almeida A, Faustino MAF, Neves MGPMS (2020) Antimicrobial photodynamic therapy in the control of COVID-19. Antibiotics (Basel) 9:320. https://doi.org/10.3390/antibiotics9060320
20. Moghissi K, Dixon K, Gibbins S (2020) Does PDT have potential in the treatment of COVID 19 patients? Photodiagn Photodyn Ther 31:101889. https://doi.org/10.1016/j.pdpdt.2020.101889

21. de Carvalho FG, de Fucio SB, Sinhoreti MA, Correr-Sobrinho L, Puppin-Rontani RM (2008) Confocal laser scanning microscopic analysis of the depth of dentin caries-like lesions in primary and permanent teeth. Braz Dent J 19:139-144. https://doi.org/10.1590/ s0103-64402008000200010

22. Lima LM, Motisuki C, Spolidorio DMP, Santos-Pinto L (2005) In vitro evaluation of probiotics microorganisms adhesion to an artificial caries model. Eur J Clin Nutr 59:884-886. https://doi. org/10.1038/sj.ejcn.1602158

23. Peng X, Xu X, Li Y, Cheng L, Zhou X, Ren B (2020) Transmission routes of 2019-nCoV and controls in dental practice. Int J Oral Sci 12:9. https://doi.org/10.1038/s41368-020-0075-9

24. Guglielmi Cde A, Simionato MR, Ramalho KM, Imparato JC, Pinheiro SL, Luz MA (2011) Clinical use of photodynamic antimicrobial chemotherapy for the treatment of deep carious lesions. J Biomed Opt 16:088003. https://doi.org/10.1117/1.3611009

25. Yu F, Du L, Ojcius DM, Pan C, Jiang S (2020) Measures for diagnosing and treating infections by a novel coronavirus responsible for a pneumonia outbreak originating in Wuhan, China. Microbes Infect 22:74-79. https://doi.org/10.1016/j.micinf.2020. 01.003

26. Sundaram M, Ravikumar N, Bansal A, Nallasamy K, Basavaraja GV, Lodha R, Gupta D, Odena MP, Ashwath RNR, Jayashree M, Intensive Care Chapter of Indian Academy of Pediatrics (2020) Novel Coronavirus 2019 (2019-nCoV) Infection: Part II Respiratory support in the pediatric intensive care unit in resource-limited settings. Indian Pediatr 57:335-342. https://doi. org/10.1007/s13312-020-1786-X

27. Gong J, Park H, Lee J, Seo H, Lee S (2019) Effect of photodynamic therapy on multispecies biofilms, including Streptococcus mutans, Lactobacillus casei, and Candida albicans. Photobiomodul Photomed Laser Surg 37:282-287. https://doi.org/10.1089/ photob.2018.4571

28. Ornellas PO, Antunes LS, Motta PC, Mendonça C, Póvoa H, Fontes K, Iorio N, Antunes LAA (2018) Antimicrobial photodynamic therapy as an adjunct for clinical partial removal of deciduous carious tissue: a minimally invasive approach. Photochem Photobiol 94:1240-1248. https://doi.org/10.1111/php.12966

29. Ricatto LGO, Conrado LA, Turssi CP, França FM, Basting RT, Amaral FLB (2014) Comparative evaluation of photodynamic therapy using LASER or light emitting diode on cariogenic bacteria: an in vitro study. Eur J Dent 8:509-514. https://doi.org/10.4103/13057456.143634

30. Rothan HA, Byrareddy SN (2020) The epidemiology and pathogenesis of coronavirus disease (COVID-19) outbreak. J Autoimmun 109:102433. https://doi.org/10.1016/j.jaut.2020. 102433

Publisher's note Springer Nature remains neutral with regard to jurisdictional claims in published maps and institutional affiliations. 